\title{
Las lenguas romances y la evangelización granadina. La aportación de Hernando de Talavera y la liturgia en arábigo de Pedro de Alcalá *
}

Romance Languages and the Evangelization of Granada. The Contribution of Hernando de Talavera and the Arabic Liturgy of Pedro de Alcalá

\author{
JESÚS R. FOLGADO GARCÍA **
}

\begin{abstract}
RESUMEN
La intuición del confesor de Isabel, la Católica, Hernando de Talavera, de promover la publicación de la «Gramática de la lengua castellana» de Nebrija buscaba la extensión de los nuevos valores que quería generar la nueva concepción de estado que promovían sus penitentes, así como la explicación comprensible de la fe cristiana. El uso de la lengua romance como vehículo transmisor de los valores que generaban la fe, fue usado también en la evangelización granadina tras su conquista, con los escritos del jerónimo fray Pedro de Alcalá, donde se promovía la celebración de la misa y la catequesis iniciática a la fe en arábigo.

\section{PALABRAS CLAVE}

Hernando de Talavera, Pedro de Alcalá, Reino Nazarí, evangelización, inculturación.
\end{abstract}

\begin{abstract}
Seeking the publication of Nebrija's «Gramática de la lengua castellana» was an intuitive move on the part of Hernando de Talavera, Isabel the Catholic's confessor. Talavera sought the promotion of the values found in the concept of State advanced by his benefactors, as well as a new comprehensible means to explain the Christian faith. The use of the romance language as a means of transmission of the values derived from the faith were used in the evangelization of Granada after its conquest along with other writings of the Hieronymite friar, Pedro de Alcalá, who favored the celebration of mass and initial Christian catechism in Arabic.
\end{abstract}

\section{KEY WORDS}

Hernando de Talavera, Pedro de Alcalá, The Nasrid Kingdom, Evangelization, Inculturation.

* Fecha de recepción del artículo: 2013-09-16. Fecha de admisión del artículo: 2013-12-16.

** Fundación San Juan. C.e.: jfolgadogarcia @ yahoo.es. 


\section{INTRODUCCIÓN}

La caída del Reino Nazarí en 1492 supuso para la Iglesia Católica un esfuerzo por llevar a gentes provenientes del mundo islámico a la fe cristiana. Esta nueva realidad implicó un planteamiento catecumenal novedoso en toda la historia de la Iglesia dirigido por el arzobispo granadino fray Hernando de Talavera, OSH. Para lograrlo, el jerónimo ideó un moderno programa evangelizador donde se conjugaba la inculturación de la fe, la celebración litúrgica y el respeto a la libertad personal. Para ello encargó a su correligionario Pedro de Alcalá la redacción del Arte para ligeramente saber la lengua aráviga [=Arte], dentro del cual encontramos un breve catecismo bilingüe y tres misas de rito romano en árabe ${ }^{1}$.

Factor esencial para esta nueva evangelización fue la promoción del uso de la lengua vernácula, bien el castellano, bien el árabe nazarí o andalusí; será ésta una constante en la vida del arzobispo jerónimo y confesor de Isabel I de Castilla, la Católica. Talavera entenderá como un elemento necesario la transmisión de los valores que los nuevos tiempos debían de generar ${ }^{2}$. Los Reyes Católicos y su reinado eran vistos por él como designio de salvación de Dios para toda la humanidad y, por ello, era necesario que al igual que el imperio romano tuvo como lengua vehicular para la transmisión de sus valores el latín, el nuevo imperio hispano tuviera su propia lengua, el castellano. Se entiende así que Talavera fuera uno de los principales promotores de la Gramática de Nebrija.

La motivación que nos ha empujado a realizar este estudio consiste en contemplar el esfuerzo de la Iglesia por evangelizar a unas gentes provenientes de un mundo con el que se había convivido desde el siglo VIII. Este empeño evangelizador servirá, además, de ensayo para afrontar la evangelización del Nuevo Mundo ${ }^{3}$. Intentaremos, por tanto, mostrar algunas adaptaciones que se hicieron en la liturgia y catequesis para lograr la evangelización del Reino Nazarí.

\footnotetext{
${ }^{1}$ La evangelización fue llevada a cabo, principalmente, con este escrito y con la Breve e muy provechosa doctrina de lo que deve saber todo christiano (cf.: FOLGADO GARCÍA, J., «Un instrumento usado en la evangelización de la Granada Nazarí: La Breve Doctrina de Hernando de Talavera", en Toletana, 24 (2011), págs. 291-307). Para comprender el proceso catecumenal en su conjunto: FOLGADO GARCÍA, J., "La iniciación cristiana de los moriscos granadinos (1492-1507)», en lacobus, 29-30 (2011), págs. 173-190.

2 Se aprecia bien la concepción de estado y de designio providencial de la Monarquía Católica en el Oficio de la Toma de Granada compuesto por el propio Talavera para festejar la Toma (cf. AZCONA, T. de, «El oficio litúrgico de Fr. Fernando de Talavera para celebrar la conquista de Granada», en Anuario de Historia de la Iglesia, 1 (1992), págs. 71-92. Para un estudio de este documento, que muestra cuál era su concepción del estado, véase MARTíNEZ MEDINA, F. J.-BIERSACK, M., Fray Hernando de Talavera, primer arzobispo de Granada. Hombre de iglesia, estado y letras. Granada 2011 (en concreto, págs. 101-137).

${ }^{3}$ Cf. GARCíA-ARENAL, M., "Moriscos e indios. Para un estudio comparado de métodos de conquista y evangelización», en Chonica nova, 20 (1992), págs. 153-175.
} 


\section{LA LENGUA VERNÁCULA Y TALAVERA}

Creemos que la vida del fraile jerónimo Hernando de Talavera ${ }^{4}$ no ha sido suficientemente valorada, a pesar de haber estado presente en las decisiones más importantes de gobierno de los Reyes Católicos. Se trata, a nuestro entender, de una de las figuras más importantes del siglo XV en la historia de España 5 . Entre sus méritos hemos de destacar, como señalamos más arriba, que fue unos de los impulsores de la redacción de la Gramática de la lengua castellana de Nebri$\mathrm{ja}^{6}$. Talavera era consciente de la importancia del castellano, no sólo para la evangelización sino también para hacer accesible y universal el conocimiento. El mis-

\footnotetext{
${ }^{4}$ Para conocer sobre su vida y obra, además de las biografías realizadas por sus contemporáneos y discípulos Jerónimo de Madrid (Breve Summa de la sancta vida del Relixiossimo fray Hernando de Talavera, Religioso que fue de la Orden del Bienaventurado San Jerónimo y Primer Arzobispo de Granada [= Breve Suma] en MARTÍNEZ MEDINA, F. J.-BIERSACK, M., Fray Hernando de Talavera, primer arzobispo de Granada. Hombre de iglesia, estado y letras. Granada 2011, págs. 363-386) y Alonso Fernández de Madrid [Vida de Fray Fernando de Talavera. Primer arzobispo de Granada en GONZÁLEZ OLMEDO, F., S. I. (ed.), Madrid 1931] y por el biógrafo de la Orden Jerónima José de Sigüenza [WERUGA PRIETO, A. (ed.), Historia de la Orden de San Jerónimo. Tomo Il. Salamanca 2000, págs. 313-353], señalamos algunos de los escritos más recientes: LADERO QUESADA, M. A., «Fray Hernando de Talavera en 1492: de la corte a la misión", en Chronica Nova, 34 (2008), págs. 249-275; IANNUZZI, I., El poder la palabra en el siglo XV: Hernando de Talavera. Salamanca, 2009; MARTíNEZ MEDINA, F. J.-BIERSACK, M., Fray Hernando de Talavera, primer arzobispo de Granada. Hombre de iglesia, estado y letras. Granada, 2011; TAVARES, U., «Talavera, Hernando de», en BiographisichBibliographisches Kirchenlexidkon, Tomo XI. Herzberg, 1996, págs. 433-480. Importante es también el estudio realizado A. Deyermond para entender adecuadamente los propios escritos de Talavera: "Las obras perdidas de Fray Hernando de Talavera", en Boletín de Historia, 101-2 (1999), págs. 365-374.

${ }^{5}$ De guía de conciencia de la reina Isabel pasó pronto a ser consejero suyo, por lo que participó activamente en la consolidación de la monarquía. Actuó en la Guerra de Sucesión; la Guerra contra Portugal; el Concilio Nacional de Sevilla (1478); la Cruzada y Guerra de Granada (1492); y la organización de la nueva diócesis granadina, de la que fue su primer arzobispo tras su conquista. Fue también obispo de Ávila (1485-1492) y uno de los impulsores del proyecto colombino. Como ejemplo del desconocimiento de su obra podemos citar la atribución de su escrito Memoria de Nuestra Redención, impresa en Valladolid el 12 de junio de 1497 y reeditada en la misma ciudad el 12 de agosto del mismo año, a Sancho Pérez Machuca. La primera edición de esta obra la encontramos en la Biblioteca Nacional de Madrid [=BN] (Inc/2713), en la Biblioteca Nacional de Portugal [=BP] (Inc/579) y en la Biblioteca de los Franciscanos de Santiago de Compostela (Signatura 34-5-16). La segunda edición la encontramos en la Perugia Biblioteca Comunale Augusta (Copid. 1695). Hacemos tal afirmación al cotejar dichos ejemplares, en los que no está impreso el nombre del autor, con las ediciones de la misma obra llevadas a cabo en Sevilla en 1534 (Biblioteca Municipal de Évora [=BE], Century XVI, 1585), Toledo en 1573 (BN, R/40077), Sevilla en 1538 (BP, F. R. 1431), Sevilla en 1541 (BE, Century XVI, 1371), Salamanca en 1573 (BN, R/29077; BN, R/29987; Real Biblioteca del Escorial, 22-V-52) en las que los distintos editores incluyen el nombre del autor en sus textos impresos. El gran número de ediciones existentes en menos de un siglo prueba la importancia de este autor.

${ }^{6}$ Antes de la publicación de este libro Nebrija había publicado las Introducciones latinae en 1486 . El contacto entre Nebrija y los Reyes Católicos se produjo gracias al monje jerónimo, quien animó a Nebrija a dedicar a los reyes el poema Ferdinandi ac Helisabethae Hispanae regum clarissimuorum profectio ad divum lacobum. Este contacto servirá a Nebrija en el futuro, contando con el amparo de Talavera, para presentar a los monarcas su Gramática castellana. El interés de Nebrija y Talavera era fomentar el estudio del latín para la formación y el intento de reparar la ignorancia latina presente en el reino, así como la transmisión de la cultura. Para ver la interrelación entre ambos autores y conocer más sobre el tema: IANNUZZI, I., «Talavera y Nebrija: lenguaje para convencer, gramática para pensar», en Hispania, 58, núm. 228 (2008), págs. 37-62.
} 
mo Nebrija muestra en el Prólogo de su Gramática la relevancia que tuvo el jerónimo en su obra:

El tercero elemento provecho deste mi trabajo puede ser aquel que, cuando en Salamanca di la muestra de aquesta obra a vuestra real Majestad, y me preguntó que para qué podía aprovechar, el mui reverendo padre obispo de Ávila me arrebató la respuesta; y, respondiendo por mí, dixo que después de vuestra Alteza metiesse debaxo de su iugo muchos pueblos bárbaros y naciones de peregrinas lenguas, y con el vencimiento a aquellos ternían necessidad de recebir las leyes quel vencedor pone al vencido, y con ellas nuestra lengua, entonces por mi «Arte», podrían venir en el conocimiento della como agora nosotros deprendemos el arte de la gramática latina para deprender el latín?

El impulso de la lengua romance, que Talavera propició para su uso en la catequesis y la liturgia, supone una ruptura con su época, ya que la lengua utilizada por la Iglesia era la latina. Baste como ejemplo la recomendación que daba a las bernardas de Ávila, siendo obispo de esta diócesis, al darse cuenta de que las monjas no comprendían lo que rezaban: Sea siempre la lección en romance, porque la lección que no se entiende, ni se lee ni se oye como debe, ni aprovecha mucho leerse ${ }^{8}$. No debemos olvidar, tampoco, la exhortación que hacía a los moriscos siendo arzobispo granadino: Que los que sabéis leer, tengáis todos los libros en arábigo de las oraciones y salmos, que vos serán dados ${ }^{9}$. En esta línea se entiende que la práctica totalidad de sus obras se encuentren en castellano, de forma que pudiera ser accesible a la gran mayoría del público.

Por ello también, al igual que promovió la publicación de la obra de Nebrija, encargó al jerónimo fray Pedro de Alcalá ${ }^{10}$ la redacción del Arte así como del Vocabulista arávigo en letra castellana [= Vocabulista $]^{11}$. Ambas obras fueron publicadas por primera vez en Granada, en 1505, en un mismo tomo ${ }^{12}$. La primera de ellas se trata de una gramática para comprender el dialecto nazarí o andalusí, que toma como referen-

\footnotetext{
7 NEBRIJA, H. A. de, Gramática de la lengua castellana, Biblioteca del Real Colegio de España (Bolonia), Cod. 132, ff.3r-3v.

${ }^{8}$ De cómo han de vivir las monjas de San Bernardo en sus monasterios de Ávila, en GONZÁLEZ HERNÁNDEZ, O., «Fray Hernando de Talavera. Un aspecto nuevo de su personalidad», en Hispania Sacra, XII (1960), pág. 157.

9 Memorial, al parecer de Fray Hernando de Talavera, para los moradores del Albaicín, en GALLEGO Y BURÍN, A.-GAMIR SANDOVALL, A., Los moriscos del reino de Granada según el Sínodo de Guadix de 1554. Granada, 1968, pág. 161.

10 La única noticia biográfica que poseemos es la que él mismo nos da en el epílogo a su obra el Vocabulista, donde se presenta como: muy indigno fraile de la orden del glorioso doctor san Jerónimo, continuo familiar y confesor del R. Señor don Fray Fernando de Talavera, primero arçobispo de la dicha cibdad y muy digno religioso de la mesma orden (BN, R/2158, f. 317). Las citas las realizaremos a partir de este ejemplar. La impresión no está paginada; la foliación está escrita a mano.

11 BN, R/2158, f. 51.

12 Podemos asegurar con certeza la fecha precisa de publicación, pues en la obra se puede leer: Fue interpretada esta obra y vocabulista de romance en arávigo en la grande y muy nonbrada cibdad de Granada por fray Pedro de Alcalá (...) en el año del Señor de mil quinientos y un años. Fue impressa y acabada por Juan Varela de Salamanca, impressor en la dicha cibdad de Granada. En cinco días del mes de febrero de mil y quinientos y cinco años (f. 317).
} 
cia la realizada por Antonio de Nebrija, tal como el mismo fray Pedro nos indica en el prólogo ${ }^{13}$. La segunda era un diccionario bilingüe castellano-nazarí. Ambos escritos, Arte y Vocabulista, de claro carácter pedagógico, se imprimieron juntos ${ }^{14}$ con el fin de facilitar la comunicación y el diálogo entre los cristianos y los moriscos granadinos. Además, se trata de los primeros escritos árabes llevados a la imprenta ${ }^{15}$.

Como ya hemos señalado, en el Arte se encuentra un breve catecismo bilingüe que sirvió de instrumento para los evangelizadores; junto a él figuran los textos litúrgicos, traducidos al nazarí, del Ordinario de la misa y de tres misas votivas: In honore beatissime Virginis Marie, In honore Sanctissime Trinitatis e In honore Sancti Spiritus.

Esta promoción del uso de la lengua vernácula se pondrá también de manifiesto en la incorporación del nazarí en el Oficio litúrgico, así como en el cambio de los textos latinos por canciones populares en el nuevo arzobispado granatense, por indicación de su arzobispo ${ }^{16}$.

\section{EL ARTE, UN INTENTO DE DIÁLOGO CON LOS PROVENIENTES DEL ISLAM}

A partir del capítulo CCCVIII del Arte, que lleva por título Regla para conocer la escritura aráviga, los comienzos y fines de las partes, se recoge el catecismo y

13 BN, R/2158, f. 51.

${ }^{14}$ Se conservan tanto en la Biblioteca Capitular de Toledo (impr. 77.30) como en la Biblioteca Nacional de España (R/2158); existe otra edición posterior que lleva por título Arte (...) enmendada y añadida y segundamente imprimida en 1506 (BN, R/2306). Se trata de un ejemplar de formato más pequeño que los anteriores, cuyo contenido no varía respecto al objeto de nuestro estudio. Ambos textos son tenidos en cuenta en la edición de LAGARDE, P. de (ed.), Petri Hispani de Lingua Arabica Libri Duo. Gotinga,1883.

15 Cf. ROMERO DE LECEA, C., «Hernando de Talavera y el tránsito en España del manuscrito al impreso", en Studia Hieronymiana, vol. I. Madrid, 1973, pág. 360.

${ }_{16}$ Su primer biógrafo nos refiere: En lugar de responso hacía cantar algunas coplas devotísima correspondientes a las lecciones, de esta manera atraía el varón de Dios tanta gente a los maitines como a la misa, otras veces hacía hacer algunas representaciones tan devotas que eran más duros que piedras los que se echaban lágrimas de devoción (Breve Suma, 373). Años más tarde de su muerte encontraremos esta crónica, que pone de manifiesto su innovación litúrgica, escrita por Luys del Mármol y Carvajal en su Historia de la rebelión y castigo de los moriscos del reino de Granada: Nuestras bodas, Zambras y regocijos, y los plazeres de que usamos, no impide nada al ser Christiano, ni sé cómo se puede dezir que es cerimonia de Moros; el buen Moro nunca se hallaba en cosas tales, y los alfaquíes se salían luego que comenzaban las zambras a tañer o cantar, y aún quando el Rey Moro yva fuera de la ciudad atravesando por el Albayzín, donde avía muchos Cádiz y alfaquís que presumían ser buenos moros, mandava cesar los instrumentos hasta salir a la puerta de Elvira, y les tenía este respeto. En Africa, ni en Turquía, no ay estas zambras; es costumbre de provincia y si fuesse cerimonia de seta [secta], que cierto es que todo avía de ser de una mesma manera. El Arzobispo santo [Talavera] tenía muchos alfaquís y meftís amigos, y aún asalariados, para que le informases de los ritos de los Moros, y si viera que lo eran las zambras, es cierto que las quitara o a lo menos no se preciara tanto dellas; porque holgava que acompañasen el Santísimo Sacramento en las procesiones del día del Corpus Christi y de otras solemnidades donde concurrían todos los pueblos a porfía unos de otros qual mejor zambra sacava. Y en la Alpuxarra, andando en la visita, quando dezía missa cantada, en lugar de órganos, que nos los avía, respondían las zambras y le acompañavan de su posada a la iglesia. Acuerdome que quando an la misa se volvía al pueblo, en lugar de Dominus boviscum, dezía en Arábigo: y barisucún, y luego respondía la zambra [ZAYAS, R. de, La música en el Vocabulista Granadino de Fray Pedro de Alcalá 1492 -1505 (Sevilla, 1995) 26]. 
las misas arábigas ya mencionadas. Posee dos grandes secciones, una de contenido doctrinal y otra de contenido litúrgico. De la primera de ellas debemos destacar la amplitud concedida a todo lo referente al sacramento de la confesión, como las indicaciones para los confesores y el examen de conciencia bilingüe para ayudar al neo-penitente proveniente de la fe musulmana; todo ello orientado a la participación eucarística. En la segunda sección, la litúrgica, sobresalen las misas referidas, así como los textos de la palabra de Dios escritos en nazarí17.

El catecismo recoge las oraciones esenciales de la fe cristiana únicamente en andalusí, queriendo por tanto que los moriscos aprendieran las verdades de la fe católica en su propia lengua ${ }^{18}$. Junto a ellas encontramos la Breve colación para los clérigos que confiessan los cristianos nuevos ${ }^{19}$; seguidamente se enumeran los pasos que se han de realizar en una buena confesión: qué cosa es confesar ${ }^{20}$; cómo se ha de hacer la confesión; qué cosa es comulgar y cómo se ha de recibir la santa comunión. No debemos tampoco pasar por alto el hecho de que la confesión se realiza en árabe, lo que sin duda facilita la práctica del sacramento al recién convertido. A continuación encontramos un examen de conciencia bajo el título: Sobre el interrogatorio y doctrina para los confesores en cada una de las lenguas. Resaltamos cómo se advierte al lector — confesor, se entiende - sobre la importancia de comprender la dificultad que puedan encontrar los conversos de lengua arábiga $^{21}$. Al hilo del examen sobre los mandamientos inquirirá también acerca de los pecados mortales (que identifica con los capitales) ${ }^{22}$, las obras de misericordia ${ }^{23} y$ los siete sacramentos ${ }^{24}$. Concluye todo lo referente a la penitencia con la enumeración de los artículos de la santa fe católica, divididos en los que pertenecen a la humanidad de Jesucristo y a su divinidad. La sección doctrinal se cierra con la explicación de los sentidos corporales ${ }^{25}$, las siete virtudes ${ }^{26}$ y la forma del sacramen-

17 Debemos destacar en este lugar la falta de estudios específicos sobre dichos temas, a pesar de encontrarnos con una novedad en la historia de la Iglesia comparable a los intentos evangelizadores de Cirilo y Metodio, y que servirán de «prólogo» a la obra evangelizadora en América.

18 Arte, ff. 22-22v. Agradecemos la traducción de los textos originales a la filóloga Oumnia Rachid, Universidad de Helsinki (Departamento de Lenguas Modernas).

19 Arte, f. 23ss. Nos encontramos aquí con un interesante compendio, a modo de vademécum, en el que se proporcionan al confesor y al penitente los elementos claves en lo referente al sacramento de la penitencia en su relación con la participación eucarística.

20 Los enunciados de los tres puntos vienen enumerados en el f. 23 y los irá desglosando a continuación. Nosotros los transcribimos en nuestro trabajo.

${ }_{21}$ Cada una de las lenguas tiene su manera de hablar y con aquélla se deve el hombre cuerdo conformar, quanto buenamente pudiere, porque de otra manera más sería enfuscar que interpretar lo que onbre quisiere dezir. E por esso en el presente interrogatorio muchas de las preguntas van así al pie de la letra sacadas parte por parte en el aravia porque lo sufrió la lengua, y otras no así porque no lo sufrió la lengua, mas solamente la misma sentencia aunque por otros términos. $Y$ lo presente sea dicho por aquellos que son inclinados a reprehender y no a defender la obras de los prójimos (Arte, ff. 27-27v.).

22 Arte, ff. 35v-38.

23 Arte, ff. 38-38v.

24 Arte, ff. 39-40.

25 Arte, f. 41.

26 Arte, f. 41. 
to del matrimonio ${ }^{27}$, así como la de la sancta comunión a los enfermos arávigos ${ }^{28}$ (con formulario en árabe), signo de la preocupación porque el neófito comprendiera el sentido de la acción sacramental.

La parte más propiamente litúrgica representa una novedad en la historia de la Iglesia, como ya hemos destacado. Comprende una traducción al árabe nazarí del Ordinario de la misa, así como de los formularios de las tres misas ya citadas; al lado de esto encontramos también el Prólogo del Evangelio de San Juan ${ }^{29}$. Alcalá limita el uso del latín a las rúbricas y a la oración secreta. Un detenido examen de los misales de la época demuestra que nos encontramos ante traducciones de los mismos y no ante una nueva composición ${ }^{30}$.

La elección de las misas votivas de la Virgen, del Espíritu Santo y de la Trinidad tiene por finalidad introducir a la población morisca en los misterios centrales de la fe católica y darle a conocer sus principales protagonistas. Merece la pena destacar que mientras para los «cristianos viejos» la celebración era exclusivamente en latín, para los conversos sería en su propia lengua, con la seguridad de que así la celebración de los misterios iría posibilitando la conversión mediante la mistagogía. Se trata, por consiguiente, de un atrevido intento de inculturación de la fe anterior a la reforma luterana.

Pasamos a explicitar los formularios de las misas y del Ordinario al que nos estamos refiriendo:

- El Ordinario de la misa ${ }^{31}$ :

La confesión de la misa (incluye dos versículos sálmicos) ${ }^{32}$, Psalmus 43 , Confiteor Deo, Kyrios, Gloria, Sequentia sancti evangelii (previa a la lectura del evan-

27 Arte, f. 41.

28 Arte, ff. $41 \mathrm{v}-42$.

29 Viene precedido con el título Euangelium Sancti lohanis (Arte, ff. 46v-47). En el f. 48 podemos leer: El Evangelio de San Juan. In principio erat verbum en arávigo.

30 Missale Mixtum secundum ordinem et regulam sancta ecclesie Toletane Yspaniarum metropolitane, Venecia, 1483 (BCT, 80-1) [=Misal Toledano de 1483]; Missale secundum consuetudinem Romanae Curiae, s. XV (BCT, 73-19); Missale secundum consuetudinem Romanae Ecclesiae, Venecia, 10 de noviembre de 1497 (BCT, 84-15); Missale mixtum almae ecclesiae Toletanae, Toledo, 1 de junio de 1499 (BCT, 80-2); Missale Romanum secundum consuetudinem fratrum ordinis sancti hieronimi, Archivo del monasterio del Parral, Segovia, 1510 [= Misal Jerónimo de 1510]. Cf. FERNÁNDEZ COLLADO, A., et alii, Catálogo de impresos de la Biblioteca Capitular. Catedral de Toledo. Toledo, 2009. En concreto, nos inclinamos a pensar que nuestro autor tiene ante sí el Misal Toledano impreso en 1483, ya que posee un apéndice donde se recoge un breve catecismo similar al que precede a nuestras misas (Bajo el título Incipit manualis liber stiones ordinem ad celebrandum ecclesiastica sacramenta, a partir del f. $249 \mathrm{v}$ y hasta la interrupción, debido a la falta de algunos cuadernillos, encontramos la explicación de lo siguiente: artículos de la santa fe católica, los siete sacramentos, los diez mandamientos, las virtudes cardinales, los siete pecados mortales (se refiere a los capitales) y las virtudes contrarias, catorce obras de misericordia corporales y espirituales).

${ }^{31}$ Arte, ff. $42 v-44$ (en el f. 48 se encuentra el índice en español y no ya en latín donde podemos leer: El ordinario de la missa en arávigo).

${ }^{32}$ Sal 124, 8 (nuestro auxilio es el nombre del Señor...) y del Sal 43, 4 (me acercaré al altar de Dios...). 
gelio), Credo, Prophatio (únicamente inicio y fin del prefacio), Sanctus, Paternoster, Agnus e Ite missa est ${ }^{33}$.

- Missa in honore beatissime Virginis Mariae ${ }^{34}$.

Introitus (Salve Sancta Parens) ${ }^{35}$, Oratio (Concede nos famulos tuos), Epistola (Eclo 24, 9-12), Graduale (Benedicta et venerabilis. Virgo dei genitrix. Post partum. Salve virgo mater dei. Que est ista tam), Alleluia (Virga iesse floruit. Ora pro nobis pia virgo ${ }^{36}$, [Evangelium] secundum lucham $(\mathrm{Lc} 11,27-28)^{37}$, Offer. $(\mathrm{Fe}-$ lix namque), Secreta ${ }^{38}$, Communio (Beata viscera) y Posc. ${ }^{39}$ (Sumptis domine).

- Missa in honore Sanctissime Trinitatis ${ }^{40}$ :

Introitus (Benedicta sit), Oratio (Omnipotens sempiterne deus), Epistola (2Cor 13, 11-13), Graduale (Benedictus es domine qui intueris), Alleluia (Benedicte Deus celi quia fecit. Qualis pro), [Evangelium] secundum lohannem (15, 26-16, 4a), Offer. (Benecitus sit deus), Secreta ${ }^{41}$, Communio (Benedicamus Deum caeli) y Posc. (Proficiat nobis).

- Missa in honore Sancti Spiritus ${ }^{42}$ :

Introitus (Spiritus Domini), Oratio (Deus qui corda), Epistola (Hch 8, 14-17), Graduale (Beata gens cuius), Alleluia (Veni Sancte Spiritus), Iterum alleluia (Emitte Spiritum); [Evangelium] secundum lohannem (14, 23-31), Offer. (Confirma hoc Deus), Secreta ${ }^{43}$, Communio (Factus est repente) y Posc. (Sancti Christus).

${ }^{33}$ La no inclusión del canon muestra cómo los destinatarios eran los sacerdotes encargados de la evangelización, recitándose en latín y voce summisa, pues si no se habría traducido también al nazarí [cf. BUX, N., La Reforma en Benedicto XVI. La liturgia entre innovación y la tradición (Madrid 2009) 38].

${ }^{34}$ Arte, ff. 44-45; Misal Toledano de 1483, ff. 164-164v; Misal Jerónimo de 1510, ff. CCL-CCLv (en este se añade la «misa de la purificación» y sólo recoge el texto que transcribe Alcalá).

35 Transcribimos los textos litúrgicos únicamente con su incipit.

${ }^{36}$ En el Misal Toledano de 1483 se añade un texto para Tempore resurrectionis, que no aparece en este texto.

${ }_{37}$ Sucedió que estando él diciendo estas cosas, alzó la voz una mujer de entre la gente y dijo: «Dichoso el seno que te llevó y los pechos que te criaron» Pero él dijo: «Dichosos más bien los que oyen la Palabra de Dios y la guardan». Junto al texto de Lucas aparecen también otros dos textos evangélicos en el Misal Toledano de 1483: uno de San Lucas (1, 41b-47) y otro de San Juan (19, 25-27). La elección de este pasaje de San Lucas responde, tal vez, al deseo de presentar a María, Madre de Dios, como modelo de creyente.

${ }^{38}$ Está en latín correspondiendo al del Misal Toledano de 1483.

39 Esta rúbrica abreviada, que hace referencia a la oración de poscomunión, aparece tan sólo en la segunda edición del Arte.

40 Arte, ff. 45-45v; Misal Toledano de 1483, ff. 165-165v; Misal Jerónimo de 1510, ff. CCXLVIVCCXLVII. Es comprensible la elección de esta misa para hacer profesión de fe en la Trinidad divina ante unos fieles provenientes del mundo islámico que la negaban.

41 Está en latín, correspondiendo al del Misal Toledano de 1483.

42 Arte, ff. 45v-46v; Misal Toledano de 1483, ff. 165v-166; Misal Jerónimo de 1510, ff. CCXLVIVCCXLVIII. Con esta misa se querría pedir al Paráclito que instruyera en el conocimiento de la fe a aquellos que participaran.

43 Está en latín, correspondiendo al del Misal Toledano de 1483. 
Junto a la traducción de los textos eucológicos sobresale la traducción de los textos de la Escritura, lo que supone una ruptura con la tradición medieval que guarda relación con el movimiento de renovación eclesial de la época que englobamos bajo el nombre de Devotio Moderna. Hay que poner esta novedad en relación al proceso evangelizador impulsado por Talavera y la innovación que la Orden de San Jerónimo supuso en la iglesia española ${ }^{44}$.

\section{CONCLUSIÓN}

Nuestro estudio pone de relieve la importancia de la lengua romance para poder hacer comprensible la fe de la Iglesia. Este hecho manifiesta el empeño por situarse en la mentalidad y la lengua del cristiano al que se dirigían, fuera "cristiano viejo» o converso, además de respetar el proceso de conversión. El Arte, con la traducción de las oraciones más comunes y, sobre todo, de los formularios de las misas, la recepción del viático y la extremaunción, supone una ruptura muy significativa con las costumbres religiosas de la época. Nos hallamos, pues, ante un hito de la inculturación de la fe en la historia de la Iglesia.

El influjo de Talavera en la Corte sirvió para redactar la primera gramática en lengua castellana que, como hemos señalado, sirvió como vehículo transmisor de la nueva sociedad que generó el reinado de los Monarcas Católicos. Estos nuevos valores para la construcción de la sociedad moderna frente a la concepción medieval tendrá como ideólogo primario al confesor jerónimo como uno de los principales adalides. Además, la búsqueda de la ansiada conversión de la población nazarí tuvo como efecto cultural la primera sistematización impresa del árabe andalusí que serviría para la evangelización de la población morisca. De esta forma, nuevamente, la Iglesia católica se convirtió en promotora cultural.

Esta realidad será determinante a la hora de afrontar la colonización y evangelización del Nuevo Mundo descubierto. La experiencia en el Reino Nazarí servirá como ensayo para afrontar los nuevos retos que se plantearon. El laboratorio granadino será además un lugar en el que se ensayaron los métodos de cristianización para los aborígenes mesoamericanos, donde el uso de las lenguas autóctonas como factor catequético será esencial.

El uso de la lengua que buscará Talavera y su confesor Pedro de Alcalá, servirá también para hacer de la participación en la liturgia de la Iglesia, en particular de la eucaristía, un elemento de catequización esencial. De aquí el intento por traducir los textos litúrgicos, de la misa y de las Horas. Un rasgo tan original como éstos sólo lo comprenderemos teniendo en cuenta la condición monástica de los autores. Nos encontramos así entre el siglo XV y XVI con lo el Concilio Vaticano II

${ }^{44}$ Estudié los orígenes de la Orden en «Nacimiento y expansión de los jerónimos y su relación con la dinastía Trastámara»: lacobus 31-32 (2012), págs. 133-152. 
afirmará a mitad del siglo XX: el uso de la lengua vulgar es muy útil para el pueblo en no pocas ocasiones, tanto en la Misa como en la administración de los sacramentos y en otras partes de la liturgia, se le podrá dar mayor cabida (Sacrosantum Concilium 36, 2) ${ }^{45}$.

Los procesos de traducción también demuestran la importancia que tenía para la Iglesia la conversión sincera de los nazaríes. Fray Hernando y fray Pedro abrían así una vía novedosa y ciertamente avanzada a su tiempo que hacía que la Orden Jerónima se situara en la vanguardia de la evangelización granadina y fuera seguida por toda la Iglesia en la evangelización colombina. Inculturación de la fe, celebración litúrgica y respeto por la libertad personal constituyen, en definitiva, tres pilares sobre los que se asienta este moderno programa evangelizador, cuya validez traspasa los límites de su contexto histórico.

Sin embargo, ponderando los esfuerzos de la iglesia granatense en tiempo de los Reyes Católicos, al proyectar un proceso catecumenal para acercar al mundo musulmán a la fe cristiana y proponiéndolo como modelo de evangelización para nuestras categorías contemporáneas, en un mundo donde la política, la sociedad y la religión estaban unidas, como en el siglo XV y XVI, y ante una sociedad como la musulmana, todo el sistema fue visto como una muestra de tibieza por parte de los cristianos. Las conversiones fueron bastantes escasas.

45 No debemos pasar por alto la prohibición del Concilio Ecuménico de Trento, en su 22. a sesión del 17 de septiembre de 1562, donde se prohibía el uso de las lenguas vernáculas en la celebración litúrgica (cf. DENZINGER, H.-HÜNERMANN, P., El Magisterio de la lglesia (Barcelona 2000) n.ำ 1749). 